\title{
Percepção dos produtores de assentamentos rurais do Agreste Meridional de Pernambuco sobre plantas tóxicas para animais de produção
}

Jaianne Keitt Alves de Melo, João Marcelo Cavalcante de Almeida, Marcos Pinheiro Franque, Luiz Carlos Fontes Baptista Filho, Taciana Rabelo Ramalho Ramos

Universidade Federal Rural de Pernambuco (UFRPE), Garanhuns, PE, Brasil

*Autor correspondente

e-mail: taciana.rrr@gmail.com

\section{Resumo}

O presente trabalho foi realizado no período de maio a outubro de 2015, com o objetivo de avaliar a percepção dos produtores de assentamentos rurais do Agreste Meridional de Pernambuco sobre plantas tóxicas para o rebanho. Para tanto, 101 produtores rurais de assentamentos rurais de Iati, Águas Belas e Itaíba foram entrevistados com uso de um questionário semiestruturado. Após a análise descritiva dos dados, a bovinocultura foi relatada como atividade principal por 63,37\% (64/101) dos produtores entrevistados, seguida da ovinocultura com 52,48\% (53/101), equideocultura com 32,67\% (33/101) e caprinocultura e suinocultura com 15,84\% (16/101). Em relação ao sistema de produção, 68,32\% dos produtores relataram adotar o sistema extensivo. Quanto à habilidade em identificar uma planta tóxica, 76,24\% (77/101) dos entrevistados declararam saber identificá-las; 76,26\% mencionaram a presença de plantas tóxicas em suas propriedades; e 43,59\% (44/101) relataram a ocorrência de casos de intoxicação no rebanho causada pela ingestão das mesmas. Quanto ao reconhecimento das plantas tóxicas, 89,11\% (90/101) dos produtores relataram conhecer Prosopis julifora (algaroba); 85,15\% (86/101) Mimosa tenuiflora (jurema preta); 81,19\% (82/101) Amaranthus spinosus (bredo); 76,24\% (77/101) Piptadenia macrocarpa (angico preto); 71,29\% (72/101) Senna obtusifolia (mata pasto); 62,38\% (63/101) Sida carpinifolia (vassourinha); 59,41\% (60/101) Aspidosperma pyrifolium (pereiro); 56,44\% (57/101) Lantana camara (chumbinho); 52,48\% (53/101) Senna occidentalis (fedegoso); 50,50\% (51/101) Ricinus communis (mamona); 49,50\% (50/101) Indigofera suffruticosa (anileira); 44,55\% (45/101) Crotalaria retusa (guizo de cascavel), Solanum paniculatum (jurubeba) e Ipomoea asarifolia (salsa); 34,65\% (35/101) Centratherum brachylepis (perpétua); 28,75\% (29/101) Ipomoea fistulosa (canudo); 25,74\% (26/101) Ipomoea sericophylla (salsa, jitirana); 24,75\% (25/101) Enterolobium contortisiliquum (tamboril); 23,76\% (24/101) Froehlichia humboldtiana (ervanço); 23,76\% (24/101) Leucaena leucocephala (leucena); 22,77\% (23/101) Manihot 
spp. (mandioca); 19,80\% (20/101) Cnidoscolus phyllacanthus (favela); 12,87\% (13/101) Turbina cordata (capoteira); 8,91\% (09/101) Brachiaria spp. (braquiárias); 2,97\% (03/101) Cestrum laevigatum (coerana), Luetzelburgia auriculata (pau-mocó), Ipomoea riedelii (anicão) e Thiloa glaucocarpa (sipaúba). Prosopis julifora foi a planta tóxica mais citada pelos produtores, porém não foram relatados casos de intoxicação por esta planta, provavelmente devido ao fato de ser necessária a ingestão de pelo menos 50\% a 75\% da dieta por um período mínimo de três meses. Assim, mesmo com 64,36\% dos entrevistados tendo acesso à assistência técnica, alguns produtores se contradisseram quanto ao conhecimento sobre plantas e sua ocorrência na propriedade, o que fomenta o desenvolvimento de ações de capacitação e orientação direcionadas aos assentados, para que os mesmos possam agir preventivamente frente às intoxicações por plantas. 